\title{
Corrigendum
}

\section{Corrigendum to "Mechanical Properties of Polyethylene-Carbon Nanotube Composites Synthesized by In Situ Polymerization Using Metallocene Catalysts"}

\author{
Mamdouh A. Al-Harthi ${ }^{1,2}$ and Bijal Kottukkal Bahuleyan ${ }^{3}{ }^{3}$ \\ ${ }^{1}$ Department of Chemical Engineering, King Fahd University of Petroleum and Minerals, Dhahran 31261, Saudi Arabia \\ ${ }^{2}$ Center of Excellence in Nanotechnology, King Fahd University of Petroleum and Minerals, Dhahran 31261, Saudi Arabia \\ ${ }^{3}$ Department of General Studies, Yanbu Industrial College, P.O. Box 30436, Yanbu, Saudi Arabia \\ Correspondence should be addressed to Bijal Kottukkal Bahuleyan; kbijal@gmail.com
}

Received 16 November 2020; Accepted 16 November 2020; Published 28 November 2020

Copyright (c) 2020 Mamdouh A. Al-Harthi and Bijal Kottukkal Bahuleyan. This is an open access article distributed under the Creative Commons Attribution License, which permits unrestricted use, distribution, and reproduction in any medium, provided the original work is properly cited.

In the article titled "Mechanical Properties of PolyethyleneCarbon Nanotube Composites Synthesized by In Situ Polymerization Using Metallocene Catalysts" [1], author Bijal Kottukkal Bahuleyan was affiliated to Department of General Studies, Yanbu Industrial College, P.O. Box 30436, Jubail, Saudi Arabia, which is incorrect. The correct affiliation for the author "Bijal Kottukkal Bahuleyan" is "Department of General Studies, Yanbu Industrial College, P.O. Box 30436, Yanbu, Saudi Arabia."

\section{References}

[1] M. A. Al-Harthi and B. K. Bahuleyan, "Mechanical properties of polyethylene-carbon nanotube composites synthesized by in Situ polymerization using Metallocene Catalysts," Advances in Materials Science and Engineering, vol. 2018, Article ID 4057282, 5 pages, 2018. 